\title{
Acerca del método de la observación y algunos alcances al estudio experimental para la construcción de imágenes
}

\section{Pérez Rivera, Ricardo}

\section{Resumen:}

El artículo expone el desarrollo de la construcción de una imagen en base a métodos de observación previos en los que se destacan características perceptuales.

Palabras clave: observación percepción - diseño.

$\left(^{*}\right)$ Diseñador Gráfico, magister en Diseño mención Comunicación Visual. Jefe de Carrera Diseño Gráfico.

Docente Área Taller de Observación, Instituto Profesional Santo Tomás, Santiago de Chile.

El desarrollo de la capacidad de "diseñar" se encuentra intrínsecamente vinculado a la inteligencia de "crear", la creatividad en diseño se puede entender en dos planos fundamentales. Uno, el plano subjetivo en el cual cada sujeto fragua su experiencia sobre el mundo (sobre la base de patrones y estereotipos definidos por la historia subjetiva de su propia cultura) y va determinando su idea (conceptualización) y conciencia del mundo, el segundo plano es el objetivo al cual el sujeto accede única y exclusivamente a través de su cuerpo (una compleja red sensible), con el que capta los estímulos posibles en el marco de ciertos parámetros sensoriales que determinan la capacidad perceptual del sujeto.

La observación es un método que busca en principio ampliar la acción coordinada del proceso perceptual. Para ello explora el esclarecimiento y desarrollo de la "conciencia sensible", es decir que el individuo tome conciencia del acto sensible y de sus consecuencias en la determinación de su idea del mundo, a través del acto mismo de percibir "el mundo", que en el rigor de lo perceptual se encuentra construido de luz, forma y espacio. En esa visión podemos inferir que cualquier percepción es una particular e intrínseca relación entre la luz, la forma y el 
espacio las consecuencias interpretativas, sus significaciones y conceptualizaciones son ocurrencias posteriores en el plano subjetivo del individuo.

El método adiestra a poner entre paréntesis ambas etapas, de manera tal de adquirir una nueva conciencia más próxima al modo en que el mundo se estructura, configura y conforma para nuestra conciencia.

El desarrollo de la "inteligencia sensible" que busca el método, concluye un conocimiento sensible y lo hace catalogando y analizando perceptualmente la información que recoge de la luz, de la forma y del espacio, en un esfuerzo atencional que va conformando las diferencias de las relaciones estructurales con que la luz, la forma y el espacio determinan la "realidad". Con una práctica regular del método ganamos o más bien recuperamos para nuestra conciencia el orden natural de ella misma, iniciándose en la sensibilidad del cuerpo y su percepción, testigos únicos de nuestro contacto con el mundo y a partir de ello reordenar el entramado de interpretaciones, significaciones y simbolizaciones que pueblan nuestro pensamiento.

Este conocimiento que potencia y posibilita, ahora permite proponer creativamente recreando o replanteando relaciones básicas y fundamentales como también complejas y trascendentales objetivadas en diseños dispuestos en los diversos ámbitos de la convivencia, la expresión, la comunicación y la representación cultural.

De lo visible

Lo visible que las cosas poseen es lo que la observación captura, recupera, como poniendo entre paréntesis, las complejas relaciones que las cosas, hechos y fenómenos sostienen en la realidad objetiva, pero ahora, no en su totalidad sino aprehendiéndolas desde su visibilidad, al decir esto figuramos al observador situado contingentemente, y en esta contingencia se vincula a lo observado como una nueva relación, el ver, un ver que va atrapando, que va transmutando el mundo en un registro consciente y es justo eso, en principio, esa transmutación, esa transustanciación por la que accedemos a la observación y al conocimiento que nos genera.

En el acto de observar debemos comprender los complejos mecanismos por los cuales nuestra conciencia se va construyendo, los procesos por los cuales nuestra observación se hace pensamiento, entendiendo que nuestro pensar, incluso, es una representación del mundo y como tal debe suceder en una inteligencia, en un acoplamiento representativo, en principio electro químico para luego transmutarse en lenguaje.

Entonces lo primero a reflexionar es acerca de ¿cómo? La realidad percibida en imagen se hace lenguaje, esta conversión de la que no siempre se está consciente es fundamental para comprender, sobre todo, la naturaleza que la imagen posee y desde ahí sus funciones tanto en el desarrollo de la conciencia y su conocimiento como en las interacciones constantes y continuas que el sujeto debe ejercer cotidianamente, para mantener su mapa de mundo vigente y en éste poder figurar su propia individualidad.

El método como ejercicio no busca alejarse del estudio de "lo observado". Por ello se conserva el acto contingente e inmediato de observar como el que gatilla la palabra, el nombre, la constatación, luego de reconocida la relación palabra/ fenómeno y sin perder esa vinculación se desgranan, por un lado la palabra en sus significaciones y por el otro el objeto, hecho o fenómeno en sus relaciones luz, forma, espacio. De ello podemos recomponer a través de una "observación" un pensamiento sensible que nos deja en el sentido de la obra, nos sitúa y revalida en el camino de crear. 
Entonces la observación es un método para el estudio de las relaciones dadas en nuestra conciencia desde la objetividad a la palabra, el nombre, pero no como un proceso que transcurre desde lo objetivo y luego se subjetiva, siendo esa subjetivación el interés para nuestra conciencia, sino que enlaza y atesora esa vinculación, ese reinicio que nos mueve y permite direccionar y reunir nuestro pensamiento a la materia y al objeto dándole sentido a la técnica, a la expresión, a la representación, a la obra.

El entorno inmediato percibido es el testimonio más fiel, que le podemos dar a nuestra conciencia de nuestra existencia y desde esa certeza aventurarnos a existir. Nuestra cultura es la resultante de una enmarañada trama de mapas individuales, históricamente contrastados entre sí y en sí, consensuados, generalizados, sintetizados hasta establecer una compleja estructura de abstracciones que nos guían, prestan sentido y sobre todo nos confirman nuestra existencia, nuestra identidad. A esta compleja estructura abstracta y subjetiva, de retorno, la hemos representado aquí en la objetividad de tal suerte de hacer visible y sensible esa manera de existir y ordenar la vida y también como a nuestra matriz subjetiva, la estamos continuamente restaurando y completando.

Del ejercicio de la observación

La observación cuenta con una herramienta de registro y estudio, que es el croquis, el croquis no es un dibujo, el croquis es un apunte que registra con la línea y sus achurados, de un modo inmediato esa realidad que, con mi sensibilidad alerta, voy atrapando, voy desconectando hasta construir un fragmento de realidad visible, constituyéndola en un objeto, que tiene tanto de mi manera de ver como de las complejas relaciones lumínicas, morfológicas y espaciales que hacen visible la realidad y que yo busco desentrañar para comprender su asociación con el lenguaje. El tiempo lineal del registro (croquis), que imita y desdobla ese complejo de relaciones a través de la contingencia entre el ojo, la mano y la técnica vinculados en el trabajo arduo de copiar la realidad en líneas, de rehacer lo observado, es este acto entonces un acto de reflexión (objetivo/ subjetivo) que le da tiempo a la conciencia para comprender esos hechos en lo de sensible que poseen, prestándole al pensamiento tiempo sensible, para ir reconstituyendo y completando ese mapa de la visualidad con esa información que es inmediatamente reflexionada, otorgándonos conceptos e ideas, observaciones latentes para la organización de un conocimiento.

Cabe ejemplificar la diferencia con la fotografía dado que si la utilizáramos como medio para la observación, ella nos privaría de la oportunidad de desentrañar meticulosamente las relaciones objetivas para ir tejiéndolas al lenguaje.

Este ejercicio constante de una observación alerta y reflexiva, que vincula el ojo, la mano, la técnica, la realidad y el pensamiento, no puede sino desarrollar y fortalecer un pensamiento sensible que me lleve a la intención de re vincular en mi conciencia la realidad en dos sistemas representativos, uno, la percepción y el otro, el lenguaje.

La percepción es un sistema primario y original de nuestra naturaleza humana, por lo cual fundamento del lenguaje, que no nombra sino lo que la percepción recoge y le representa, entonces separar cuidadosamente el nombre de lo que nombra recuperando para la conciencia la originalidad del contacto sensible con el mundo, para analizar y comprender los secretos que lo hacen estimulo, objeto, hecho, fenómeno y realidad ante mi 
conciencia y su lenguaje. Esta es una etapa en la que debemos acompañar a nuestros estudiantes para ayudarlos a comprender lo que desdoblan.

El croquis, lo hemos dicho, no es un dibujo y no lo es porque va asociado al lenguaje. Lo utilizamos para nombrar y constatar este proceso de reducción sensible que le hacemos a nuestra comprensión del mundo, a la observación de lo que realmente le interesa, no es el nombre sino lo que nombra, justo aquello que está antes de la palabra y allí solo están la luz, la forma y el espacio. Entonces nos valemos del lenguaje para establecer un paralelo al apunte recogido en dibujo, quedando expuestos y vinculados, esta asociación en donde el dibujo recoge lo que observo y la palabra lo refiere, es a lo que llamamos la observación. Ahora la observación posee etapas, mismas que el método asume, antes que todo comienza en una relación definida por la obviedad, propia de nuestro cotidiano donde la interacción con las cosas, los hechos y los fenómenos siempre es lateral a nuestra rutina, caracterizada fundamentalmente por el ensimismamiento provocado por la convicción de que el mundo está allí, porque siempre allí ha estado y allí tiene que estar, es esa consecuencia la que nos permite establecer una relación rutinaria con el mundo, que nos abstrae de la contingencia e inmediatez.

Es esta obviedad, la que la atención debe atravesar, ese estado de alerta de no caer en el encantamiento cotidiano propio del sentido común, entonces el primer paso ha de ser desprenderse del sentido común, ya que las interacciones que este establece con el mundo no están en las cosas, sino más bien están puestos en un modelo que le sobreponemos a la realidad a riesgo de hacerla desaparecer.

El observador repara en la cosa, en el hecho, en el fenómeno al que nombra y constata, luego de haber eludido el primer sentido, la relación se abre a nuevos sentidos más profundos y trascendentes.

\section{La constatación}

Entonces al constatar, el observador repara en la cosa, en el hecho, en el fenómeno y lo nombra, comprueba aportando la identificación, una definición de límites a priori, cuestión que en el caso de una cosa no resulta ser un proceso complejo, un árbol, una silla, la percepción capta en una barrida las diferenciaciones, figura fondo, texto contexto, pero en el caso de otros "objetos" de mayor complejidad el proceso de la constatación muchas veces trae el nombre pero no recoge con claridad lo que nombra. Evidentemente a la observación le interesa ir a la cosa (a lo de visible que la cosa posee) no al nombre, este solo es una estación, una referencia que nos conecta con la idea de las cosas pero no con las cosas, entonces apoyado en esta referencia, conectarse al objeto y ahí definir sus límites, su estructura y sus características.

El croquis es una validación de que lo observado efectivamente se refiere a lo visible y no a un prejuicio o a un conocimiento de otro orden, pues si el dibujo lo recoge y la palabra lo nombra, lo refiere develando ese encadenamiento reflejo, pensamiento, imaginación, percepción y realidad es la recuperación de esa cadena, la que me da conciencia de lo observado.

\section{La observación verdadera}

La segunda etapa es la observación propiamente tal, es decir cuando se logra a partir de la constatación romper la obviedad y recuperar la especificidad de lo observado, logrando desconectarlo de la idea general de mundo, que nuestro sentido común construye para otorgarnos una relación (aunque abstracta) integral con el mundo, 
una vez en suspenso con el mundo, el observador le da origen al mundo reiniciándolo a partir de lo observado, (ya no a partir de sí mismo).

Ejemplo: se le encarga al estudiante ir a observar el "orden" de un árbol, con el propósito de que profundice en el análisis de dicho fenómeno, dado que muestran una relativa familiaridad con el concepto y su significado, sin embargo tienen grandes dificultades para construirlo.

El estudiante observa el follaje y al no reconocer un "orden" lo denomina "caos". Lo más probable es que denomine caos al no reconocimiento de un orden. Entonces el uso de los conceptos como unidades representativas de la realidad posee evidentemente sus límites. Es frecuente que el nombre que le damos a una cosa, a un hecho o a un fenómeno se estructure con otros conceptos para explicar no la cosa, el hecho o el fenómeno, sino, la significación o la explicación de la cosa, hecho o fenómeno, hasta entonces nuestros observadores permanecen en el lenguaje, ocultándose en nuevos conceptos que levemente tocan la realidad para devolverse en la comodidad de su generalidad y abstracción.

La observación requiere de la permanencia en la realidad y que el lenguaje sea doblegado para describirla en primera línea. Entonces ¿Cuál es el orden del follaje de ese árbol?, todo orden requiere de una referencia, un "lo que ordena", entonces ¿que ordena el follaje de un árbol?, se aporta un ejemplo a los estudiantes: ¿Qué ordena la sala de una casa?, ¿qué sabe la dueña de casa que le da orden a esa sala? ¿Qué le permite decidir casi "matemáticamente" la posición de los muebles, el color de los muros y el tipo adornos y decoraciones? Ella sabe su voluntad de cobijar y organiza la sala para el recibimiento, toda la casa se ordena para acoger, pero particularmente la sala lo hace para acoger la reunión, todo en ella tiene la medida de la reunión, la distancia del dialogo, sin duda el primer orden lo da el cuerpo, pero en la casa y especialmente en la sala es la comodidad con la que se acoge el cuerpo. Ahora, ¿que ordena el follaje de ese árbol? Con esa pregunta el estudiante puede volver a observar.

En su breve croquis traía también otras constataciones, "sensación de confusión" (esta constatación más bien se dirige a él mismo, repara en el modo en que está sintiendo lo observado), lo que es una nueva vuelta a lo de caos, pero también dice "y movimiento" (ahora se dirige al objeto). Observa, probablemente, la dirección de las distintas ramas, pero para eso él tuvo que determinar un comienzo y un fin, ve que el árbol crece, la dirección es un primer orden, que tiene consecuencias en la forma y su manera de estar en el espacio, todo el árbol es una huella de esa dirección, de ese movimiento, va de abajo hacia arriba, asciende, pero lo hace de una particular manera, "fluida", insinúa el estudiante, comienzan a asomarse algunas respuestas, ya no caos, ahora "un movimiento ascendente y fluido, que rodea, para evitar la interrupción y la saturación”. Esa frase ya posee la estructura de una observación, porque está generando paralelamente al objeto (al árbol) una estructura conceptual que lo imita y se mantiene sujeta a él, sin desprenderse a la generalidad y abstracción propias del lenguaje. La observación mueve al imaginario a comprender, a develar el complejo relacional luz, forma y espacio que constituye lo observado.

El estudiante puede seguir profundizando su estudio e intentar, ahora desentrañar la "fluidez", ¿qué es lo que nombra?, descubrirá que es relativa a la forma o mejor dicho es un tipo de relación entre la forma y el espacio, con eso aumentarán los antecedentes con los cuales, observación tras observación desentrañará el árbol. 
Este cúmulo de observaciones, una despertada por la otra, lo pueden llevar a constituir un fundamento para lo cual el estudiante realiza láminas de síntesis que le permiten (al taller) comprender y definir el complejo de observaciones y desarrollar una "macro observación" definiendo un sentido común para las observaciones obtenidas en el estudio previo, ese fundamento devela ordenes que orientan la construcción de la obra y la vinculan a una cadena de sentido. Por ejemplo una imagen artificial, al construirla con un propósito comunicacional, se deben estudiar los objetos, hechos o fenómenos que se ordenarán en la construcción. Cada objeto "despegado" de la realidad trae consigo una nebulosa de connotaciones y cuando en el "escenario" de la imagen lo aproximo a otro objeto, casi como una respuesta sináptica se vincularán provocando una resultante connotativa, este resultado no puede ser gratuito si el fin es comunicar, la observación nos permite recoger desde él o los contextos del contenido a exponer, las luces, los materiales, la organización, puntos de vista, encuadres con los que podremos componer nuestra imagen. El fundamento me impulsa y guía a crear, no en el invento sino siguiendo la ruta trazada por el método, que no observa cualquier fenómeno, sino aquellos que considere pertinentes para la representación.

\section{Acerca de la construcción de imágenes}

La idea de construcción de imágenes, se entiende desde la premisa que la imagen es un objeto sensible y como tal todos sus componentes estructurales lo son. Se pueden determinar entonces, para la imagen primera (la perceptual) tres materiales fundamentales, luz, forma y espacio.

Toda imagen está hecha de una particular relación entre estos materiales, cada imagen con la cual interactuamos a través de la percepción, está constituida de una compleja relación entre luz, forma y espacio... una imagen solo es distinta a otra, porque la relación entre la luz, la forma y el espacio son distintas entre ellas. Entonces todo constructor de imágenes ha de ser antes de todo un experto en la luz, en la forma y en el espacio y sobre todo en las relaciones que estos "materiales" sostienen entre sí para determinar las diversas representaciones de la realidad, si bien es cierto que cada uno de ellos son variables que nunca pierden su intrínseca relación, al variar uno, varia el otro y toda la realidad implica esa subyugación. El constructor deberá desconectar un fragmento de esa continuidad, solo la sensibilidad desarrollada como pensamiento a través de la observación le posibilitará realizar ese trabajo con el control y precisión que requiere.

Fragmentos de realidad, que ahora solo adquirirán sentido al interactuar con un sujeto que le preste una "reconexión" (interpretación) en un campo subjetivo, aun así ese tráfico solo se podrá realizar a través de la percepción. Por ello toda imagen construida debe materializarse y objetivarse, pues toda imagen es en el cuerpo, es éste quien la construye tanto para el caso natural (imagen perceptual) como para las imágenes artificiales.

La experiencia humana en el reconocimiento de las diversas manifestaciones de la realidad, tiene un extenso desarrollo, muchos de sus aspectos son producto de una transmisión a nivel genético, que toda especie posee, directamente vinculada a la sobrevivencia, que nos hace selectivos, regulando nuestras relaciones con la realidad, realidad entre comillas, pues deberíamos decir "nuestra realidad perceptual". Esta regulación obviamente busca el reconocimiento de la diferencia entre lo favorable y lo desfavorable para el individuo y su sobrevivencia, y en ello va la oscuridad, la tranquilidad, la inquietud, muchas de estas interpretaciones que le damos a nuestra percepción de la realidad ya poseen una respuesta emocional, ahora cada cultura, cada familia y finalmente cada individuo crea y desarrolla un complejo interpretativo, por lo cual nuestra interpretación de "la 
realidad" en gran medida esta predeterminada por nuestra genética, nuestra cultura, nuestro entorno familiar y por nuestros propios e íntimos razonamientos.

Un experto en la imagen debe dedicar gran parte de su estudio a conocer y comprender estos repertorios interpretativos, dado que la interacción que un perceptor tiene con una imagen, será enfrentada y resuelta por esos mismos canales que el sujeto ha desarrollado, en sus interacciones inmediatas y contingentes con el contínuum de su existencia. De hecho, cuando la imagen se hace objeto, es decir, está afuera con los otros objetos (una ilustración, una fotografía por ejemplo) y al prestarle atención reconocemos en ese objeto una serie de manchas, llenas, vacías, cuya organización posee semejanza (grado de iconicidad) con mis experiencias preceptúales (un paisaje, una persona, mi propia imagen, etc.), que yo entiendo como la realidad, pero esta imagen objeto es un artificio técnico o tecnológico, el cual también reconozco y acepto, ahora como una representación intencionada y manipulada de esa realidad.

Es este tipo de imágenes las que construimos nosotros los diseñadores, además de reproducir un aspecto especifico y particular de la realidad, deben reconstituir el contexto visible, de manera que nuestro perceptor acceda a una realidad replanteada e intérprete una intención indicativa a manera de "mensaje" y de vinculo "transubjetivo". La interpretación es un mecanismo propio de la naturaleza humana, inmediato y contingente que se despliega desde la realidad percibida, la que nuestro imaginario reconstituye y válida para nuestra conciencia, efectuándolos procesos representativos para la emoción y sus reflejos sensibles con el cuerpo o/y para la abstracción del lenguaje y su pensamiento.

En este ejercicio constructivo y experimental fundamentalmente interesa que el estudiante sea capaz de establecer controladas y fundamentadas interacciones entre la luz, la forma y el espacio de la misma manera en que el carpintero decide y controla clavos, madera y técnica, nuestro constructor decida por encuadres, puntos de vista, luces, atmósferas, coordinándolos de manera tal de hacer sensible y evidente su contenido.

\section{Audiovisual}

Nuestra percepción es una exploración de la realidad o más bien de algunos aspectos de ella, el hecho de que nuestro cuerpo se encuentre inserto en la constancia y continuidad del mundo nos permite generar registros selectivos y efímeros los cuales son irreproducibles pues se desvanecen en el mismo acto, quedando solo algunos aspectos sintéticos en nuestra memoria de la cual también podrán desvanecerse con el tiempo.

Solo el constante y continuo retorno de la percepción a la realidad permite reinaugurar nuestra conciencia del mundo, más bien de pequeños aspectos de él con los cuales establecemos ahora "nuestro mundo".

La capacidad inmediata, selectiva y efímera de registrar que posee nuestra percepción consigue mantener a nuestro cuerpo inserto en la "realidad" y con él a nuestra conciencia (la cual carga de significado e impone sentido a los objetos, hechos y fenómenos).Nuestro cuerpo es una coordinación de diversos "instrumentos" (órganos) que captan de un modo "holístico" su entorno centralizándolo en una sola "imagen", debemos perder el hábito de solo conceptualizar "la imagen" como un registro técnico o tecnológico, como un artificio, una ilustración, una pintura, un video o una fotografía por ejemplo, sino recuperar el concepto para la imagen original con la cual nuestra conciencia ingresa al mundo, la imagen que nos da nuestro cuerpo (perceptual), esa imagen paradojal, efímera y constante, inmediata e inconmensurable a la que definimos como "realidad", una imagen 
que nos contiene y constituye en la diferencia. Toda la "topografía" de la imagen aparece ante la percepción dado el catastro histórico que guarda nuestra conciencia y se constituye fundamentalmente en un complejo de diferencia organizada en un todo, la percepción despega una cosa de la otra, despega la figura del fondo conservado un asombroso equilibrio entre los límites que preservan la unidad. Una imagen que se articula entre diversos aspectos coordinados de un modo tal que se nos da como una armonía persistente, esta persistencia nos focaliza y permite aprehender con ese sentido de totalidad, integrando la diversidad de estados físicos con las que se nos manifiesta y nos acepta e integra como parte de ella, estamos y existimos en esa imagen inconmensurable y efímera.

El experimentar con la rutina que realiza nuestra percepción para darnos el mundo, es una conducta constante de nuestro cuerpo, como también así de nuestra conciencia. Por ello el estudio de la imagen que realizan los talleres de diseño implican la experiencia y la experimentación con los distintos parámetros que constituyen nuestra imagen del mundo, experienciar los límites y las diferencias, tanto de luz, de forma y espacio como también la unicidad persistente (Gestalt) que diferencia e integra "las cosas", hechos y fenómenos con sus "nombres" (lenguaje) en los distintos dominios (objetivo y subjetivo),en las distintas dimensiones (relaciones de tiempo y espacio), con los distintos factores y distintos aspectos, todo este entramado complejo es intuido, examinado, descifrado, interpretado, adivinado, acertado continua y constantemente por nuestro cuerpo, pero también inadvertido, confundido, omitido, engañado, errado.

La experimentación esta en nuestra naturaleza, entonces debemos hacer método de nuestra observación, descubrir y trazar el camino de nuestro estudio que claro está no solo debe ocurrir en el ámbito racional, sino también en el sensible. Desarrollar una inteligencia sensible que pueda, asociada a la inteligencia racional, crear un pensamiento creativo, un pensamiento de diseño.

Dominamos consiente e/o inconscientemente las consecuencias que tuvieron para nuestro pensamiento cultural el desarrollo de las técnicas y tecnologías del "registro", desde los originales métodos análogos hasta las actuales cámaras fotográficas, de video, celulares y distintos dispositivos móviles. Una realidad que nunca se detenía para los registros naturales del cuerpo, comienza con esos descubrimientos a fragmentarse, detenerse y descontinuarse de la naturalidad, convirtiéndose en "objetos" con su propio origen y connotación, que le presentan a nuestro conocimiento una "legitimidad" que compite, se articula y entrelaza con nuestra conciencia original del mundo. Estas imágenes artificiales se mimetizan infiltrando otros órdenes que se nos presentan a través de nuestra percepción directa y contingente, la que no diferencia entre la naturalidad y artificialidad de los objetos, solo nuestra conciencia podrá hacer esa discriminación, si ésta está en su idea y en su conocimiento, pues todas esas imágenes artificiales como los otros objetos están participando y obedeciendo, en principio, las leyes de la objetividad pero con el confidencial secreto de ser un portal condicionado y directo(una puerta secreta al espectáculo) ala subjetivación laque posee distintas y vertiginosas normas, las imágenes artificiales son objetos, pero objetos simulados que nos reinsertan en el subjetivo con un sentido manipulado, reiniciándonos con ideas ajenas, diferentes y exóticas pero pudiendo ser también inoportunas, inadecuadas e incorrectas.

La imagen artificial como medio posee características similares a los intercambios de lenguaje pero compromete de un modo directo nuestra estructura imaginaria y con ello nuestros procesos de abstracción. 
Cierto es que hemos privilegiado la visualidad, nosotros los diseñadores gráficos asumimos ese dominio como el territorio en el que debemos desenvolvernos, luz, forma y espacio como materiales a representar y por herencia la representación estática a la manera de la ilustración, pintura y de la fotografía las que gradualmente fuimos reconociendo en nuestro terreno, ahora con la misma gradualidad experimentamos con el movimiento y el sonido, complejos nuevos materiales que debemos comprender, estudio que nos exige método, técnicas y tecnologías y por supuesto, una evolución de nuestro pensamiento.

Para los que profesamos la observación como método nos aportan un hermoso desafío para nuestra experimentación, el movimiento por su complejidad y el sonido por su extrañeza. ¿Cómo se observa el sonido?, éste, como la imagen perceptual es efímero, pero además invisible. La Gestalt nos ha enseñado que para la percepción todo estimulo posee su antagónico que le permite contrastarse y definirse, un primer paso necesario en la observación es definir los límites que posee el objeto, hecho o fenómeno que observo, ese límite lo trae la diferencia, el orden que se da entre luz, forma y espacio que particulariza el objeto, la luz se define con la oscuridad, el movimiento con la quietud, y el sonido con el silencio, se hace fascinante el hecho que el sonido a pesar de que su materialidad no es visible, se encuentra sorprendentemente atado a la materia visible y nuestra sensibilidad sabe de ese esencial vinculo, en rigor el sonido es producto de una relación entre los materiales y aun cuando no está presente la causa, la conciencia la adivina, la supone, la imagina o a la inversa, cuando ocasionalmente está presente la causa pero no el sonido también lo podemos suponer. Este vaticinio ocurre como parte de la naturaleza de nuestra percepción sin que medie una reflexión o un estudio. La conciencia cotidiana entiende el espacio y la distancia cuando se oye el ladrido de un perro, el canto de pájaros, el viento en el follaje, si quiero capturar esa sensación, esa conciencia que el sonido nos da de la realidad con una fotografía, no es tarea fácil, hay que experimentar pues que el sonido completa la realidad, sabemos que como recurso comunicante completa la realidad y potencia la representación.

Toda la sorpresa y modificación que trae a nuestra conciencia y a nuestro "sentido común" la fotografía, sin duda no termina de ocurrir, es más se actualizan las sospechas e incertidumbre que nos causa con las nuevas generaciones que se aventuran "conscientemente" en esta técnica y en su tecnología, descontinuar en fragmentos congelados la realidad, sacarlos del orden para darles un artificioso nuevo origen, pero no habiendo ni siquiera archivado el asombro se nos vino el cine, hoy el video y toda la batería de recursos digitales a la siniestra disposición de cualquier "usuario".

En general la realidad suena, el sonido está implícito intrínsecamente.

Lo experimental ya no es solo el estudio de selectos grupos, sino vivimos sumergidos en una experimentación masiva, amateur e inexperta que ya sobrepasa las posibilidades de archivo y análisis. "La obra" se ha democratizado y ello ha hecho mutar su sentido continua y constantemente en una espiral ya muy fuera del alcance de la academia y la institucionalidad, pues en esta vorágine experimental se fragua la revolución propia del cambio. Ahora espectadores, las calles, las redes sociales y los espacios virtuales se "toman" los museos, se anteponen, sobreponen y continúan después de ellos. Así los límites institucionales podrían terminar desapareciendo.

Bibliografía

Merleau-Ponty, M. (1975). Fenomenología de la Percepción. Barcelona: Península. 
Merleau-Ponty, M. (1964). El ojo y el espíritu. Buenos Aires: Ediciones Paidos.

Merleau-Ponty, M. (2002). El mundo de la percepción. Buenos Aires: Fondo de Cultura Económica.

Bachelard, G. (2000). La poética del espacio. Buenos Aires: Fondo de Cultura Económica.

Bachelard, G. (1982). La poética de la ensoñación. México D.F.: Fondo de Cultura Económica.

Baudrillard, J. (1978). Cultura y simulacro. Barcelona: Kairos.

Baudrillard, J. (1997). El otro por sí mismo. Barcelona: Anagrama.

Damasio, A. (2009). En busca de Spinoza. Barcelona: Crítica.

Artículos

Prettel B., O. y Obispo R., G. Psicología de la percepción o de la forma. En www.gestalt-codeh. com.

Cruz C., A. (1959). Improvisación del señor Alberto Cruz. Primera Conferencia de Facultades Latinoamericanas de Arquitectura. Facultad de Arquitectura - Universidad Católica de Chile-Santiago. Doc. 27/12 noviembre 1959.

Rojas, S. (2014). "Ensayos / ¿Sobrevive la subjetividad a la muerte del index?” en Atlas imaginarios visuales / Atlas, Revista fotografía e imagen. http://www.atlasiv.cl/atlas

Abstract:

The article proposes the development in the image built process based on previous observation methods that focus on perception issues.

Key words: observation - perception - design.

Resumo:

O artigo expõe o desenvolvimento da construção de uma imagem baseada em métodos de observação prévios onde se destacam características perceptuais.

Palavras chave: observação - percepção - design.

Acerca del método de la observación y algunos alcances al estudio experimental para la construcción de imágenes fue publicado de la página 123 a página133 en Cuadernos del Centro de Estudios de Diseño y Comunicación Nº 66 